\title{
Numerical Simulation on the Impact Damage of CFRP Laminates with Different Porosities
}

\author{
Aying Zhang ${ }^{1,2, *}$, Dongxing Zhang ${ }^{2}$, Mingzhe $\mathrm{Qu}^{1}, \mathrm{Kai}_{\mathrm{Yu}}^{2}$ \\ ${ }^{1}$ Harbin University, Harbin 150086, People's Republic of China \\ ${ }^{2}$ Harbin Institute of Technology, Harbin 150001, People's Republic of China
}

\begin{abstract}
The influence of the porosity on the impact damage of CFRP laminates was investigated. A finite element analysis model is established by using ABAQUS software combined with the sudden stiffness degradation model. The failure criterion of the impact damage of the fabric fiber reinforced composites is proposed by improving the fiber and matrix damage failure criterion, based on the failure criterion that is suitable for the undirectional composite laminates. The impact damage of longitude fiber failure, latitude fiber failure, matrix crushing and delamination were considered for the fabric carbon fiber reinforced epoxy composites laminates. Basic strength parameters of composites are used to evaluate the mechanical properties of CFRP laminates with different porosities. The impact damage area of CFRP composites laminates are simulated accurately.
\end{abstract}

\section{Introduction}

Carbon fiber reinforced polymer matrix composites (CFRP) has been extended used in the aerospace, automobile, naval and construction industries due to outstanding strength and stiffness to weight ratios compared to conventional engineering materials [1-3]. However, CFRP laminates are relatively brittle under the dynamic loading, which seriously limit the wide application of CFRP laminates [4-6]. The composite structure made with CFRP laminates is very sensitive to the internal damage induced by the impact loading, such as a dropped wrench or runaway debris during their manufacturing and service life [7-9]. The main drawback of CFRP laminates is their weak interfaces which lead to a considerable reduction in the structural integrity caused by minor damage [10-12]. The impact damages of the composite laminates include delamination, fiber breakage and matrix cracking, which can significantly reduce their mechanical properties [13-14]. Voids are among the most common manufacturing induced defects in polymeric composites [15]. Many researchers have shown that voids have detrimental effects on the strength of CFRP laminates [16]. It is necessary to evaluate the impact damage of CFRP laminates with different void concents.

Many previous literatures have studied the numerical simulation on the impact damage of composite laminates. However, few papers have been published on the effect of voids on the impact damage of CFRP laminates. The objective of this research was to evaluate the influence of porosity and impact energy on the impact damage of CFRP laminates. The CFRP laminates of two different porosities were subjected to impact loading at five energy levels. Then the impacted specimens were performed to investigate the impact damage in the CFRP laminates of two different porosities subjected to different impact energy.

\section{Experimental}

\subsection{Materials}

The elastic constants of CFRP laminates are shown in Table 1.

Table 1. Elastic constants of CFRP laminates.

\begin{tabular}{|c|c|}
\hline Elastic constants & Value \\
\hline $\mathrm{E}_{11}(\mathrm{GPa})$ & 41 \\
\hline $\mathrm{E}_{22}(\mathrm{GPa})$ & 41 \\
\hline $\mathrm{E}_{33}(\mathrm{GPa})$ & 3.4 \\
\hline $\mathrm{V}_{12}$ & 0.03 \\
\hline $\mathrm{V}_{13}$ & 0.23 \\
\hline $\mathrm{V}_{23}$ & 0.23 \\
\hline $\mathrm{G}_{12}(\mathrm{GPa})$ & 3.6 \\
\hline $\mathrm{G}_{13}(\mathrm{GPa})$ & 2.5 \\
\hline $\mathrm{G}_{23}(\mathrm{GPa})$ & 2.5 \\
\hline
\end{tabular}

The strength constants of CFRP laminates with porosity of $0.33 \%$ and $1.50 \%$ are shown in Table 2 and Table 3.

Table 2. Strength constants of CFRP laminates with porosity of $0.33 \%$.

\begin{tabular}{|c|c|}
\hline Strength constants & Value (MPa) \\
\hline $\mathrm{X}_{\mathrm{T}}=\mathrm{Y}_{\mathrm{T}}$ & 351 \\
\hline $\mathrm{X}_{\mathrm{C}}=\mathrm{Y}_{\mathrm{C}}$ & 402 \\
\hline $\mathrm{Z}_{\mathrm{T}}$ & 51 \\
\hline $\mathrm{Z}_{\mathrm{C}}$ & 149 \\
\hline $\mathrm{S}_{12}$ & 171 \\
\hline $\mathrm{S}_{23}=\mathrm{S}_{13}$ & 54 \\
\hline
\end{tabular}


Table 3. Strength constants of CFRP laminates with porosity of $1.50 \%$.

\begin{tabular}{|c|c|}
\hline Strength constants & Value (MPa) \\
\hline $\mathrm{X}_{\mathrm{T}}=\mathrm{Y}_{\mathrm{T}}$ & 342 \\
\hline $\mathrm{X}_{\mathrm{C}}=\mathrm{Y}_{\mathrm{C}}$ & 383 \\
\hline $\mathrm{Z}_{\mathrm{T}}$ & 46 \\
\hline $\mathrm{Z}_{\mathrm{C}}$ & 137 \\
\hline $\mathrm{S}_{12}$ & 162 \\
\hline $\mathrm{S}_{23}=\mathrm{S}_{13}$ & 49 \\
\hline
\end{tabular}

T300/914 woven-fabric carbon/epoxy prepregs were supplied from Hexcel Composites Ltd. The initial fiber volume fraction $\mathrm{V}_{\mathrm{f}}$ is $58 \%$. The sequence of the laminates were $\left[( \pm 45)_{4} /(0,90) /( \pm 45)_{2}\right]_{S}$. The carbon/epoxy laminates with porosity of $0.33 \%$ and $1.50 \%$ were produced by adopting two different magnitudes of autoclave pressures.

\subsection{Impact test}

To identify the impact damage in the composite laminates, impact tests were performed using a drop-weight system, the DYNATUP model JLW-100 impact testing machine consists of a drop tower equipped with an impactor, which has a hemispherical impactor of $6.35 \mathrm{~mm}$ in radius. The total mass of the impactor was fixed at $5 \mathrm{~kg}$, resulting in an available kinetic energy by varying the height of release.

The impact energy increase from the initial impact energy of $3 \mathrm{~J}$ to the maximum impact energy of $15 \mathrm{~J}$ and the increment is $3 \mathrm{~J}$. The length, width, and the thickness of the impacted specimen were approximately $230 \mathrm{~mm}$, $25 \mathrm{~mm}, 4.5 \mathrm{~mm}$. Two different porosity levels ranging of $0.33 \%$ and $1.50 \%$ were obtained for the impact specimen.

\subsection{Failure criteria of the impact damage}

As shown in equations (1) to equations (4), the failure criterion of the low velocity impact damage of the woven-fabric fiber reinforced composites is proposed by improving the fiber and matrix damage failure criterion based on Hou's failure criterion that is suitable for the undirectional composite laminates [17].

The basic composite strength parameters are used to evaluate the mechanical properties of CFRP laminates with different porosities. A finite element analysis model is established by using ABAQUS software combined with the sudden stiffness degradation model.

Delamination $\left(\sigma_{33} \geqslant 0\right)$ :

$$
\left(\sigma_{33} / Z_{\mathrm{T}}\right)^{2}+\left(\sigma_{13} / S_{13}\right)^{2}+\left(\sigma_{23} / S_{23}\right)^{2} \geqslant 1
$$

Longitude fiber failure $\left(\sigma_{11} \geqslant 0\right)$ :

$$
\left(\sigma_{11} / X_{\mathrm{T}}\right)^{2}+\left[\left(\sigma_{12}^{2} / \sigma_{13}^{2}\right)^{2} / S_{f}^{2}\right] \geqslant 1
$$

Latitude fiber failure $\left(\sigma_{22} \geqslant 0\right)$ :

$$
\left(\sigma_{22} / Y_{\mathrm{T}}\right)^{2}+\left[\left(\sigma_{12}^{2} / \sigma_{23}^{2}\right)^{2} / S_{f}^{2}\right] \geqslant 1
$$

Matrix crushing $\left(\sigma_{33}<0\right)$ :

$\left(-\sigma_{33} / 2 S_{13}\right)^{2}+\left(Z_{\mathrm{C}}{ }^{2} \sigma_{33} / 4 S_{13}{ }^{2} Z_{\mathrm{C}}\right)^{2}-\sigma_{33} / Z_{\mathrm{C}}+\left[\left(\sigma_{13}+\sigma_{23}\right) /\right.$ $\left.2 S_{13}\right]^{2} \geqslant 1$

Where $X_{\mathrm{T}}$ is the longitude tensile strength of the woven-fabric fiber reinforced composites, $Y_{\mathrm{T}}$ is the latitude tensile strength of the woven-fabric fiber reinforced composites, $Z_{C}$ is the vertical compressive strength of the woven-fabric fiber reinforced composites, $S_{f}$ is the shear strength of fiber failure of the woven-fabric fiber reinforced composites and $S_{13}=S_{23}$.

\section{Results and discussion}

\subsection{Impact crater depth simulation}

\subsubsection{Porosity of $0.33 \%$}

Figure 1(a) to Figure 1(e) shows the images of impact stress of CFRP laminates with the porosity of $0.33 \%$ at five energy levels from $3 \mathrm{~J}$ to $15 \mathrm{~J}$.

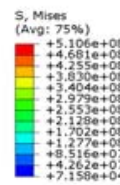

a)
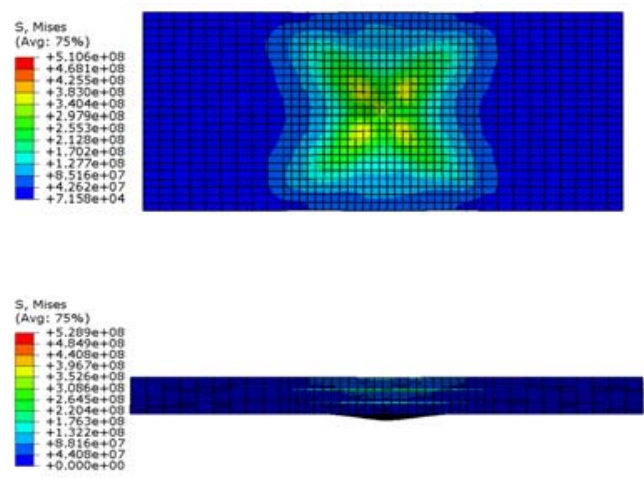

b)
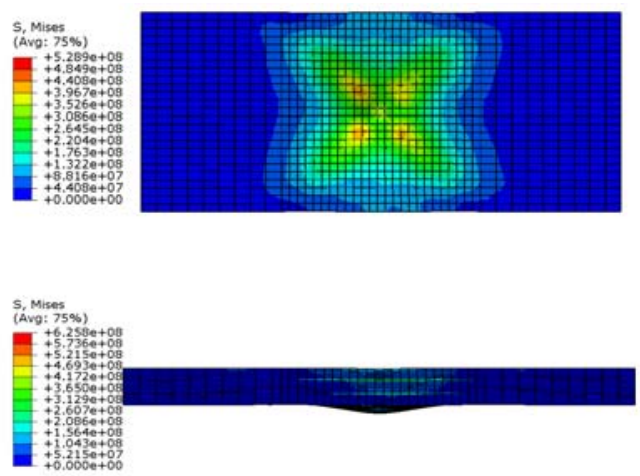

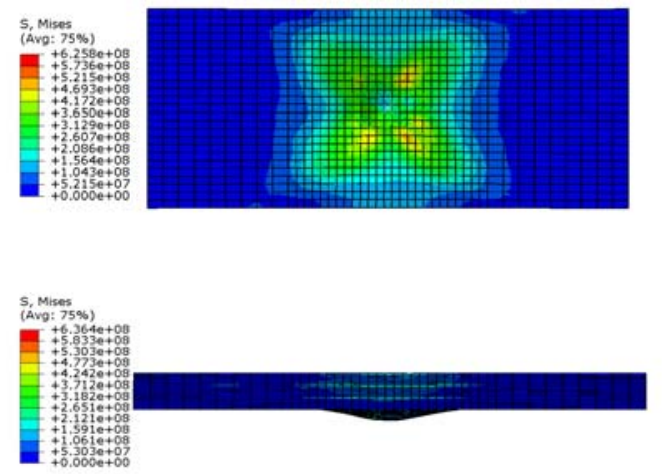

d)
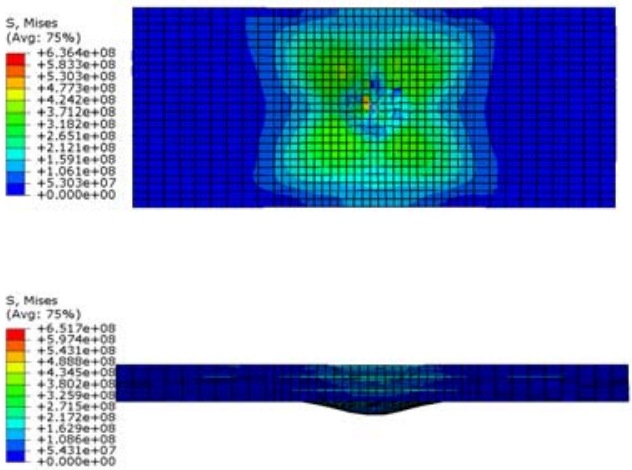

e)

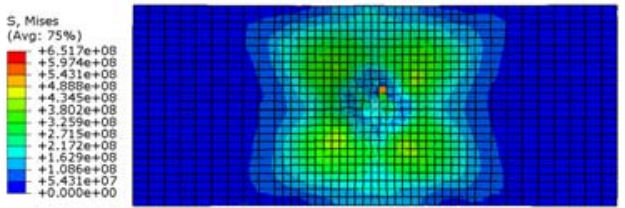

Figure 1. Images of impact stress of CFRP laminate with the porosity of $0.33 \%$.

a) $3 \mathrm{~J}$, b) $6 \mathrm{~J}$, c) $9 \mathrm{~J}$, d) $12 \mathrm{~J}$, e) $15 \mathrm{~J}$.

As shown in Figure 1(a) to Figure 1(e), the images of impact stress in the positive side of the impacted specimen distributed in X-shaped, which is because that the main sequence of the CFRP laminates were $( \pm 45)$.

Figure 1(a) to Figure 1(e) show that the region of the stress exceeds the value of 0 expanded with impact energy increased from $3 \mathrm{~J}$ to $15 \mathrm{~J}$. A larger difference of stress can be observed in the vicinity of the impact point, which reflects the internal injury situation aggravated with the increasing impact energy.

As shown in Figure 1(a) to Figure 1(e), the impact deformation at the mid-span point of the impacted specimen tended to increased with impact energy increased from $3 \mathrm{~J}$ to $15 \mathrm{~J}$. The stress of the sequence of $(0,90)$ is larger than the stress in other sequences, which indicate that the sequence of $(0,90)$ prone to delamination.

\subsubsection{Porosity of $1.50 \%$}

Figure 2(a) to Figure 2(e) shows the images of impact stress of CFRP laminate with the porosity of $1.50 \%$ at five energy levels from $3 \mathrm{~J}$ to $15 \mathrm{~J}$.

As shown in Figure 2(a) to Figure 2(e), the images of impact stress in the positive side of the impacted specimen distributed in X-shaped.
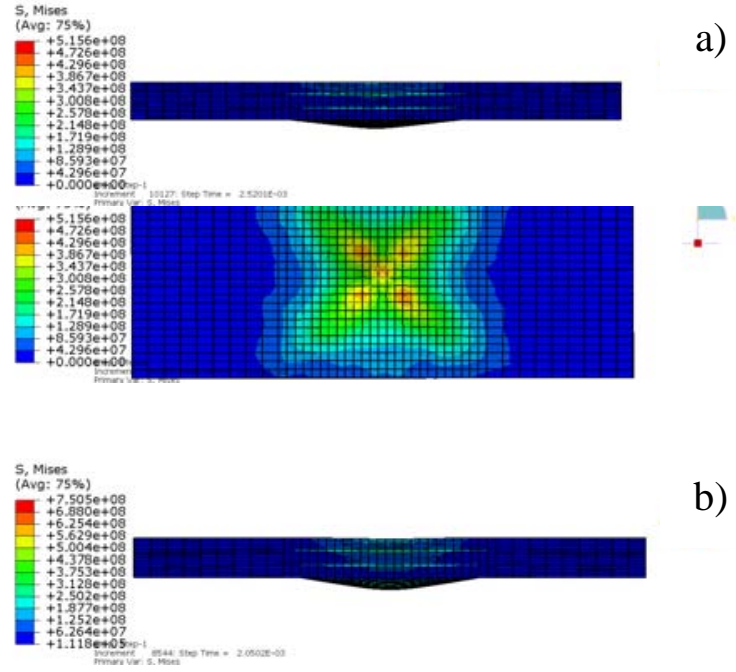

b)
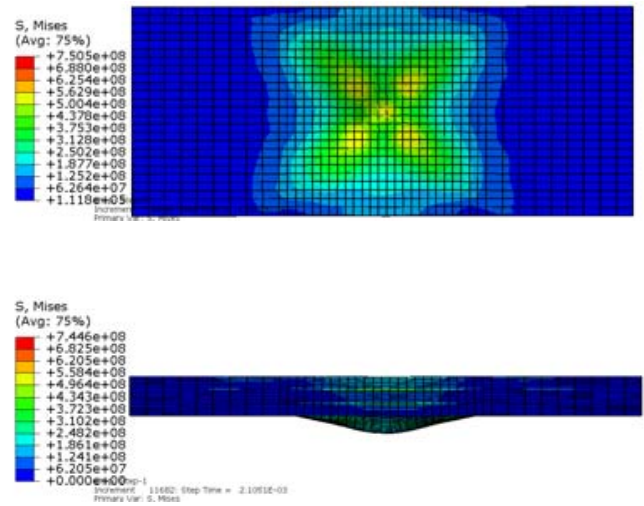

C)
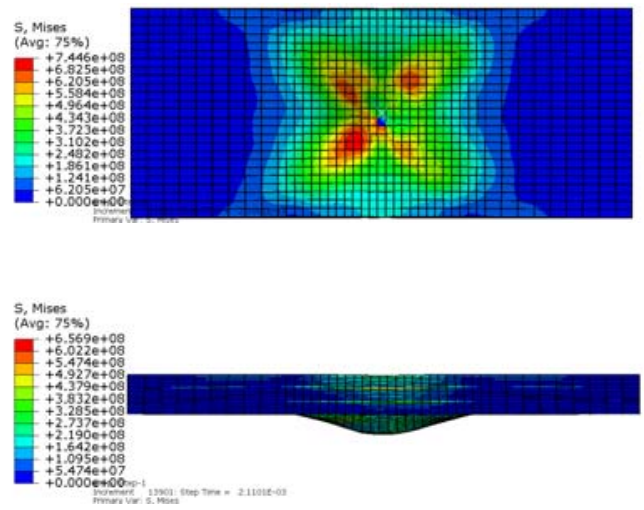

d)
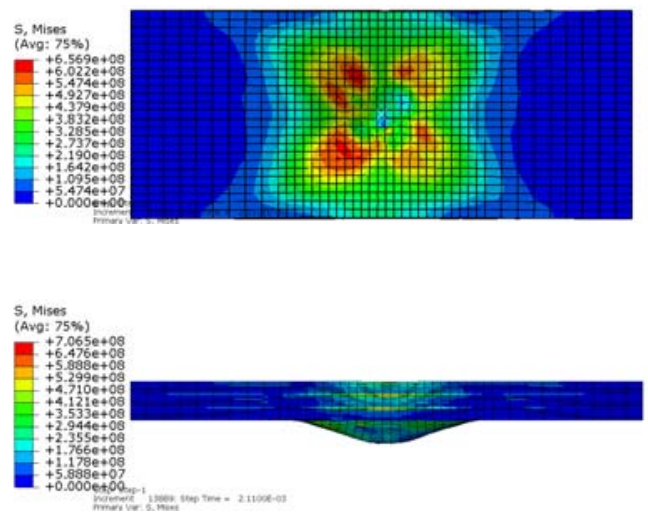

e) 


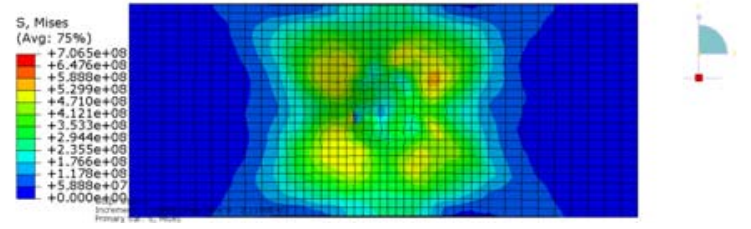

Figure 2. Images of impact stress of CFRP laminate with the porosity of $0.33 \%$.

a) $3 \mathrm{~J}$, b) $6 \mathrm{~J}$, c) $9 \mathrm{~J}$, d) $12 \mathrm{~J}$, e) $15 \mathrm{~J}$.

Figure 2(a) to Figure 2(e) show that the impact deformation at the mid-span point of the impacted specimen tended to increase with impact energy increased from $3 \mathrm{~J}$ to $15 \mathrm{~J}$.

As shown in Figure 2(a) to Figure 2(e), the same impact stress images and the variation trend. The area of impact stress in the positive side of the impacted specimen with the porosity of $1.50 \%$ is larger than that of the impacted specimen with the porosity of $0.33 \%$ at the same impact energy.

The impact deformation at the mid-span point with the porosity of $1.50 \%$ is larger than that of the impacted specimen with the porosity of $0.33 \%$ at the same impact energy.

\section{Conclusions}

The influence of the porosity on the impact damage of CFRP laminates was investigated. A finite element analysis model is established by using ABAQUS software combined with the sudden stiffness degradation model.

The failure criterion of the low velocity impact damage of the fabric fiber reinforced composites is proposed by improving the fiber and matrix damage failure criterion based on Hou's failure criterion that is suitable for the undirectional composite laminates.

The impact damage of longitude fiber failure, latitude fiber failure, matrix crushing and delamination were considered for the fabric carbon fiber reinforced epoxy composites laminates.

The basic strength parameters of composites are used to evaluate the mechanical properties of CFRP laminates with different porosities.

The impact damage area of CFRP composites laminates are simulated accurately. This paper presents an effective method for the prediction of the impact damage of the fabric fiber reinforced composite laminates with different porosities.

\section{Acknowledgements}

This work was financially supported by Heilongjiang Natural Science Foundation (Grant No. E201454).

\section{References}

[1] G. Minak, P. Morelli, A. Zucchelli. Compos. Sci. Technol. 69, 1358 (2009)
[2] P. N. B. Reis, J. A. M. Ferreira and et al: Compos. Sci. Technol. 60, 154 (2009)

[3] C. Santiuste, S. Sanchez-Saez, and E. Barbero: Compos Struct. 92, 25 (2010)

[4] T. R. Andrew, B. Richard and W. H. Giles: Int J Solids Struct. 45, 4349 (2008)

[5] M. F. S. F. Moura, A. T. Marques. Compos Part A. 33, 361 (2002)

[6] K.W. Kang, H.S. Kim, et al. Mater Sci Eng. A483484, 333 (2008)

[7] M. L. Costa, M. C. Rezende, S. F. M. Almeida. J Compos. Mater. 39, 1943 (2005)

[8] K. H. Im, C. S. Cha, et al. Compos Part B. 32, 669(2001)

[9] S.A. Baeurle, A. Hotta, A.A. Gusev. Polymer. 47, 6243 (2006)

[10] A.R. Chambers, J.S. Earl, et al. Int J Fatigue. 28, 1389 (2006)

[11]F. Awaja, B. Arhatari, et al. Polym Degrad Stab. 94, 814 (2009)

[12]P.D. Puglia, M.A. Sheikh, D.R. Hayhurstb. Compos Part A. 35, 223 (2004)

[13]B.R. Stoner, S.R. Akshay, et al. Appl Phys Lett. 99 , 183104 (2011)

[14]C.B. Parker, S.R Akshay, et al. J. Mater. Res. 27, 1046 (2012)

[15] O. Asi. Compos Struct. 90 (2009), 43

[16] V. P. W Shim, L. M. Yang. Int J Mech Sci. 47, 647 (2005)

[17] J. P. Hou, N. Petrinic, et al. Compos. Sci. Technol. 60, 273 (2000) 